\title{
PENERAPAN TEKNOLOGI WEB UNTUK MEMBANGUN SISTEM LATIHAN UJIAN NASIONAL ONLINE BAGI SMA MUHAMMADIYAH 4 KARTASURA
}

\author{
Heru Supriyono $^{1}$, Anam Sutopo ${ }^{2}$, Rahma Fitri Wahadati ${ }^{3}$, Kunti Dwi Narwattu Jati ${ }^{3}$, \\ Unsta Nastiti Lingga Rastari ${ }^{3}$, \\ ${ }^{1}$ Program Studi Teknik Elektro - Fakultas Teknik \\ ${ }^{2}$ Program Pendidikan Bahasa Inggris - Fakultas Keguruan dan Ilmu Pendidikan \\ ${ }^{3}$ Program Studi Informatika - Fakultas Komunikasi dan Informatika \\ Universitas Muhammadiyah Surakarta \\ Heru.Supriyono@ums.ac.id
}

\begin{abstract}
In 2015, Ministry of Education and Culture of Republic of Indonesia introduced online national examination systems for senior high school students to replace paper-based national examination systems. The problem faced by many schools are students are not ready to have a computer-based test because they do not have enough preparation. The root this problem is because scholls do not have an online examination systems for training their students. This paper discusses a development and application of online national examination preparation systems for SMA Muhammadiyah 4 Kartasura. The objective of the development is to provide a web based sistem which could be used for training students to face online national examination. The system was developed following system development life cycle (SDLC) principle with waterfall approach. The requirement analysis showed that the features of the systems needed by the school are involving randomizing mechanism for questions, test duration limitation, automatic marking systems, administrator functions and login systems for students and teachers. The national examination preparation systems was developed using PHP programming language dan MySQL database management systems. The result of the development is a web-based national examination preparation systems with complete features in accordance with requirement analysis. The questionaire analysis of system testing by the users involving teachers and students showed that $70 \%$ respondents feel satisfy with the developed systems.
\end{abstract}

Keywords: computer based test, online national examination, web-based test systems,

\section{PENDAHULUAN}

Evaluasi hasil belajar dalam pendidikan dilakukan terhadap anak didik untuk mengetahui tingkat kemampuan atau keberhasilan selama menjalani proses pendidikan. Evaluasi dilakukan secara berkala atau rentang waktu tertentu selama masa pendidikan. Untuk tingkat sekolah menengah atas (SMA), proses evaluasi hasil belajar selama tiga tahun diantaranya dilakukan dengan ujian akhir nasional (UAS) atau ujian Nasional (UN). Ujian nasional (UN) selama ini dilaksanakan dengan model ujian berbasis kertas dimana soal ujian dicetak dan siswa menuliskan jawaban ujian pada lembar jawab yang dibagikan. Mulai tahun 2015 pemerintah memperkenalkan model pelaksanaan 
UN baru yaitu model UN berbasis komputer (UNBK) yaitu soal tersedia dalam sistem komputer dan siswa mengisikan jawaban pada sistem komputer yang sudah disediakan. Keunggulan UNBK adalah adalah soal bisa diambil dari bank soal sehingga masing-masing siswa mendapatkan variasi soal yang berbeda namun dengan tingkat kesulitan yang sama sehingga siswa tidak bisa saling mencontek, peserta bisa langsung mengetahui hasil ujian sesaat setelah selesai mengerjakan soal. Dengan kelebihan ini UNBK sudah mulai digunakan untuk pelaksanaan ujian nasional (UN) untuk tingkat sekolah menengah atas (SMA) pada tahun 2015.

SMA Muhammadiyah 4 Kartasura merupakan sekolah menengah atas yang didirikan secara resmi oleh suatu badan usaha atau instansi swasta yang bergerak dalam bidang pendidikan formal. SMA Muhammadiyah 4 Kartasura didirikan pada tahun 1984 dengan surat keputusan atau izin Pendirian Sekolah dari Kanwil Depdiknas / Depag No. 398/L095/M.84 tanggal 26 Mei 1984 dibawah sebuah yayasan Majelis Dikdasmen Sukoharjo. Kondisi saat ini, SMA Muhammadiyah 4 Kartasura masih menggunakan model ujian dengan berbasis ujian tertulis termasuk untuk latihan ujian nasional. Permasalahan yang dihadapi oleh SMA Muhammadiyah 4 Kartasura berkaitan dengan pelaksanaan UNBK adalah belum terbiasanya siswa mengerjakan ujian dengan berbasis komputer sehingga cukup menghambat persiapan UN disekolah tersebut. Akar dari permasalahan ini adalah sekolah belum mempunyai sistem latihan ujian nasional online. Berdasarkan latar belakang tersebut maka perlu ada pendampingan penerapan sistem latihan ujian online yang bisa digunakan untuk latihan UNBK oleh siswa SMA Muhammadiyah 4 Kartasura.

\section{TUNJAUAN PUSTAKA}

Perkembangan teknologi dalam bidang komputer dan informatika sudah banyak diterapkan dalam berbagai bidang kehidupan seperti untuk sistem jual beli online bagi usaha kecil dalam bidang herbal (Rivai dan Supriyono, 2016), untuk alat bantu pemilihan rumah tinggal (Supriyono dan Sari, 2016). Dalam bidang pendidikan teknologi komputer sudah diimplementasikan untuk menyelesaikan berbagai permasalahan seperti oleh Sinurat dkk (2012) yang menguraikan bahwa teknologi web berbasis bahasa hypertext markup language (HTML) 5 bisa digunakan untuk membuat media pembelajaran IPA dan IPS yang interaktif yang lebih menarik jika dibandingkan dengan metode pembelajaran hanya dengan berbasis material cetakan saja seperti buku teks. Selain itu, Supriyono dkk (2016) mengimplementasikan sistem website yang dilengkapi dengan fitur SMS gateway untuk mengelola presensi guru, karyawan dan siswa pada sebuah sekolah menengah pertama (SMP).

\section{METODE PENELITIAN}

Pengembangan sistem ujian online dilaksanakan dengan menggunakan prinsip system development life cycle (SDLC) dengan metode waterfall, yang alur prosesnya dapat dilihat pada Gambar 1. Proses pengembangan sistem ujian online dimulai dari tahap perencanaan yang diawali dengan wawancara dengan pihak sekolah untuk menggali informasi data-data sekolah dan untuk mengetahui kebutuhan pengguna. Wawancara dilakukan kepada Kepala Sekolah dan staf-staf sekolah yang berhubungan 
langsung maupun tidak langsung dengan bagian pengolahan data termasuk kepala tata usaha dan staf teknologi informasi SMA Muhammadiyah 4 Kartasura. Data-data yang diperoleh ini kemudian digunakan sebagai bahan analisis kebutuhan pengembangan sistem termasuk fitur input dan output sesuai dengan kebutuhan. Berdasarkan hasil wawancara dan analisis kebutuhan didapatkan kesimpulan sistem yang dibutuhkan mempunyai spesifikasi utama yaitu sistem yang bersifat responsif yang bisa diakses secara online dimana saja kapan saja oleh admin maupun oleh siswa melalui media internet menggunakan berbagai macam perangkat yang berbeda ukuran layarnya seperti komputer pribadi, laptop, tablet dan telepon genggam, sistem mempunyai fitur atau kemampuan untuk menampilkan soal secara acak, sistem mempunya fitur penampilan nilai.

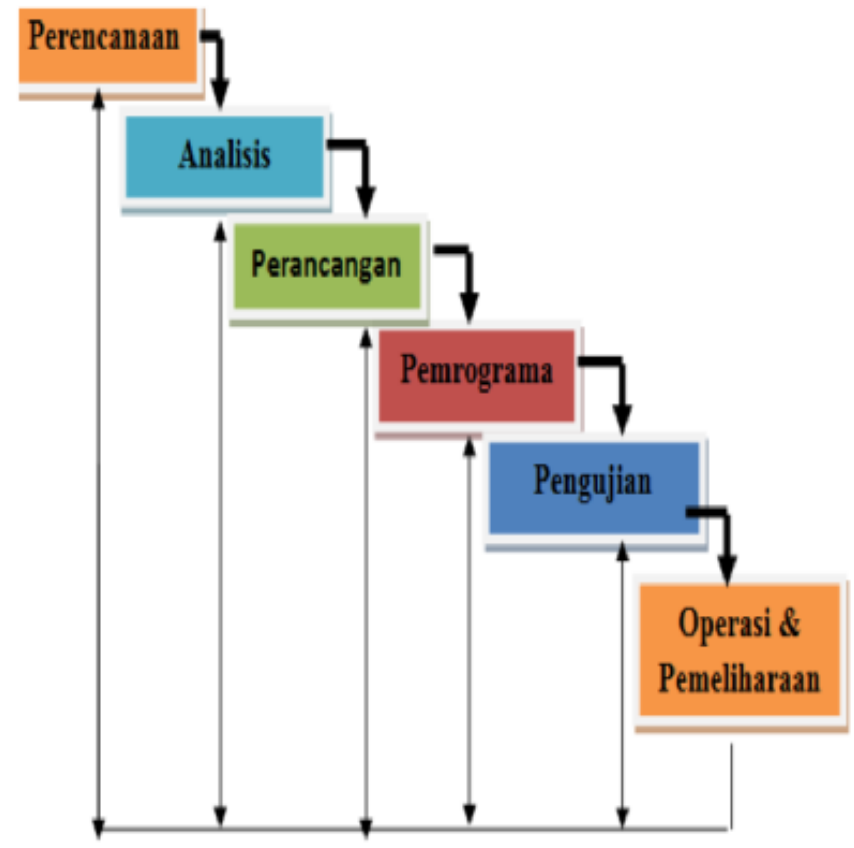

Gambar 1. Alur SDLC Waterfall

\subsection{Diagram Use Case}

Sistem yang dibuat mempunyai pengguna (aktor) dengan hak akses yang berbeda-beda meliputi administrator (admin), pengguna umum (publik) dan siswa SMA. Kemampuan masing-masing aktor digambarkan dalam diagram use case yang dapat dilihat pada Gambar 2. Di dalam use case tersebut di jelaskan bahwa admin dapat mengakses sistem ujian secara online tersebut, antara lain mengelola data yaitu create, read, update, delete (CRUD) kuis, soal, profil user, kategori, group user, tingkat kesulitan serta dapat melihat hasil kuis sedangkan publik mempunyai kemampuan untuk mengikuti ujian serta melihat hasil ujian dengan mendaftar terlebih dahulu. 


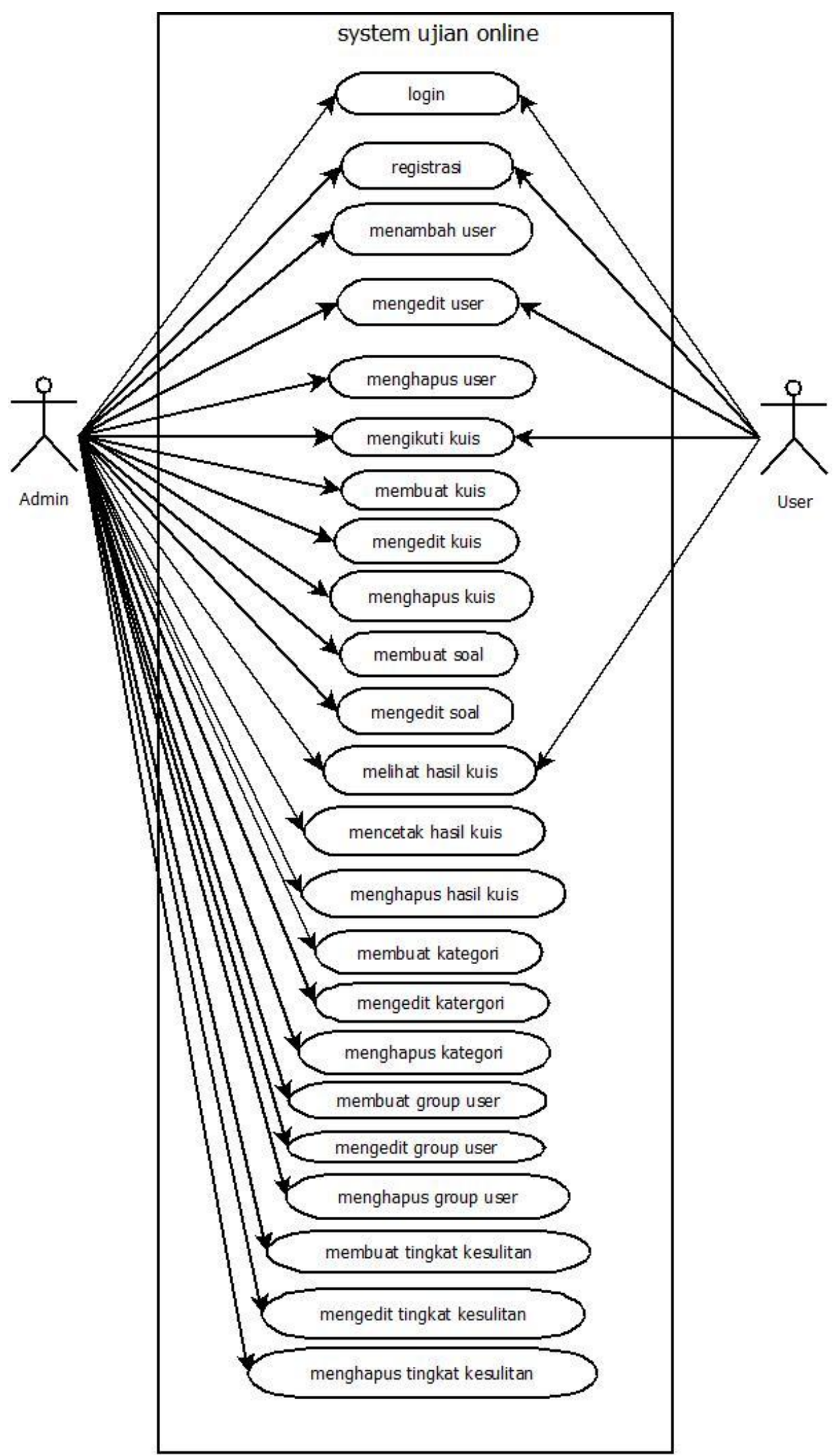

Gambar 2. Diagram use case 


\subsection{Perancangan Basisdata}

Semua data yang diolah dalam sistem ini disimpan kedalam basisdata. Sistem yang dibangun mempunyai sebuah basisdata yang terdiri dari beberapa tabel meliputi tabel user_group, users, super_admin, q_options, quiz_result, quiz_qids, quiz_group, quiz, quiz, question_category, qbank, institute_data, gcm_ids, essay_qsn, difficult_level, class_gid dan class_coment. Hubungan antar tabel dapat dilihat pada entity relationship diagram (ERD) pada Gambar 3.

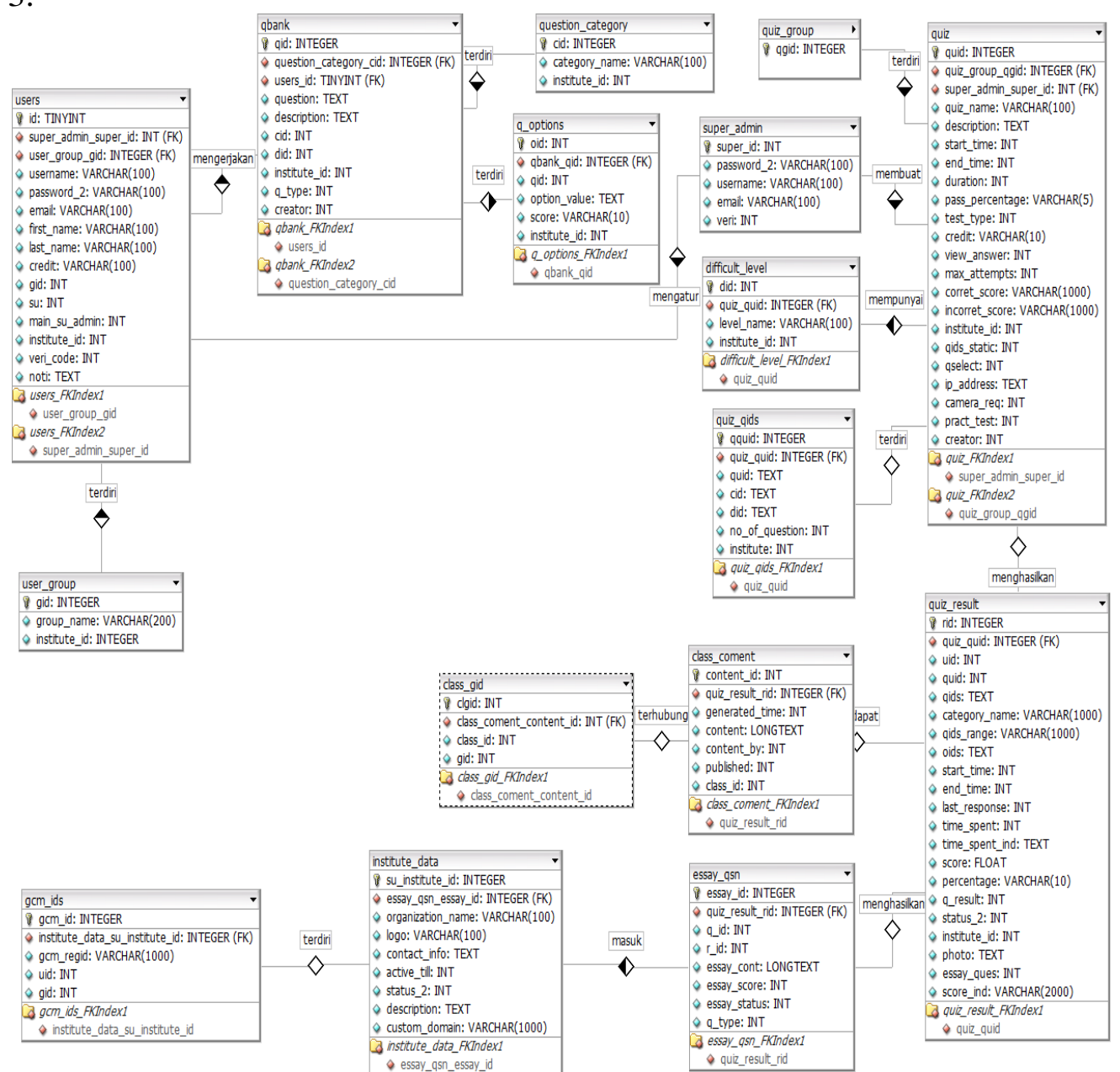

Gambar 3. Entity relationship diagram (ERD) basisdata sistem yang dibangun.

Sistem dikembangkan dengan bahasa pemrograman PHP dan sistem pengelola basisdata MySQL.

\section{HASIL DAN PEMBAHASAN}

\subsection{Hasil}

\subsubsection{Halaman Login}

Halaman login merupakan halaman utama pada sistem ujian online berbasis web pada SMA Muhammadiyah 4 Kartasura dan dirancang dengan tujuan untuk login admin, guru pengampu mata pelajaran dan siswa. Untuk hak akses seluruhnya di pegang oleh admin. Pada halaman ini, terdiri dari beberapa bagian, diantaranya: menu masuk untuk login ke website dengan menggunakan username dan password, selain hal tersebut juga terdapat menu registrasi. 


\subsubsection{Halaman Registrasi}

Halaman ini digunakan untuk mendaftar sebagai pengguna pada website ujian online SMA Muhammadiyah 4 Kartasura. Untuk melakukan registrasi diperlukan untuk mengisikan data-data meliputi username, nama depan, nama belakang, email, password, masukkan lagi password dan group kemudian klik tombol registrasi.

\subsubsection{Halaman Control Panel Admin}

Halaman control panel admin digunakan oleh admin untuk mengontrol dan mengelola website. Admin memegang hak akses terhadap website secara penuh. Berikut ini adalah bebrapa menu yang ada dalam control panel admin:

\subsubsection{Menu Dashboard}

Menu ini (Gambar 4) berisi tampilan utama control panel admin dari website diantaranya ucapan selamat datang untuk admin, kemudian terdapat juga sub menu yang terdiri dari daftar user, bank soal dan hasil.
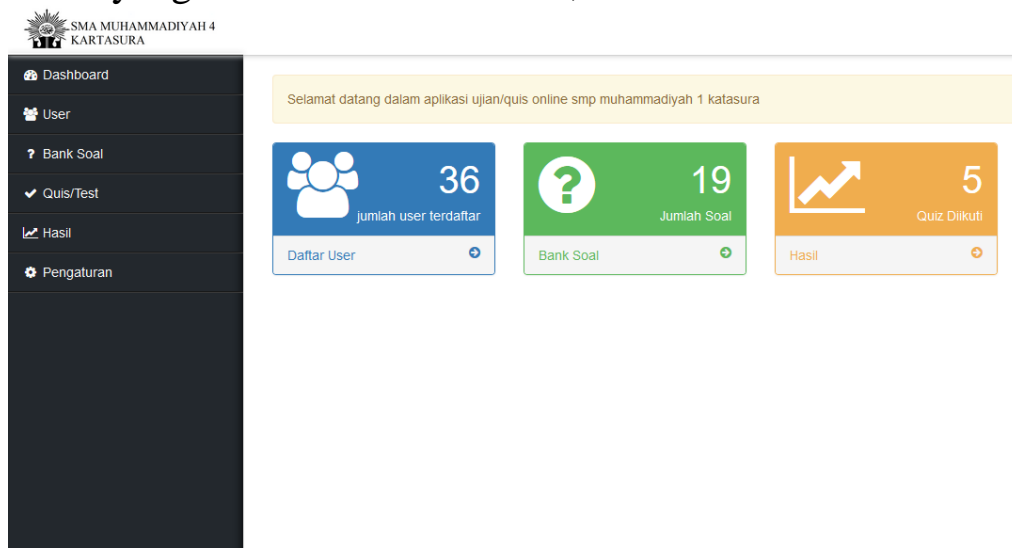

Gambar 4. Tampilan menu Dashboard

\subsubsection{Menu Daftar Pengguna}

Pada menu ini admin dapat melihat, menambahkan dan menghapus nama-nama user/siswa dan guru/admin yang dapat mengakses website. Tampilan menu daftar pengguna dapat dilihat pada Gambar 5.
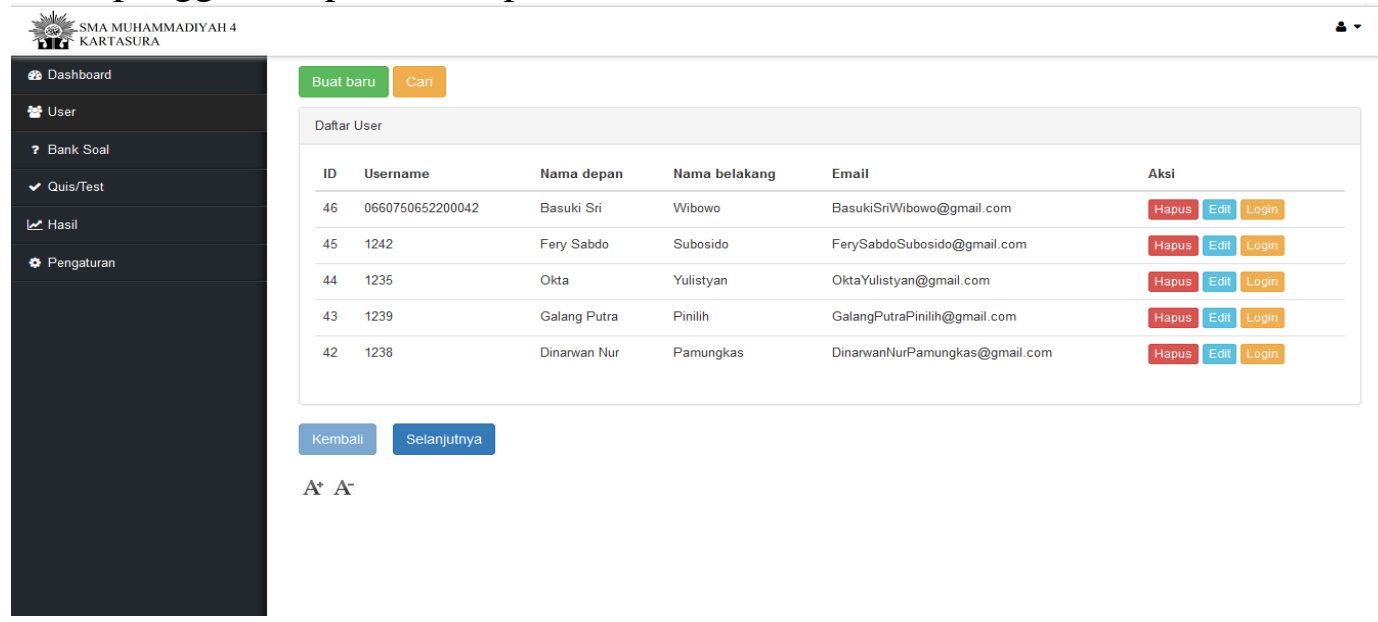

Gambar 5. Tampilan menu User 
Pada saat membuat user baru dibutuhkan beberapa data yang harus dimasukkan meliputi username, nama depan, nama belakang, email, password, masukkan lagi password, memilih group dan tipe akun yang diinginkan apakah murid, guru ataupun admin. Tampilan formulir pembuatan pengguna baru dapat dilihat pada Gambar 6.
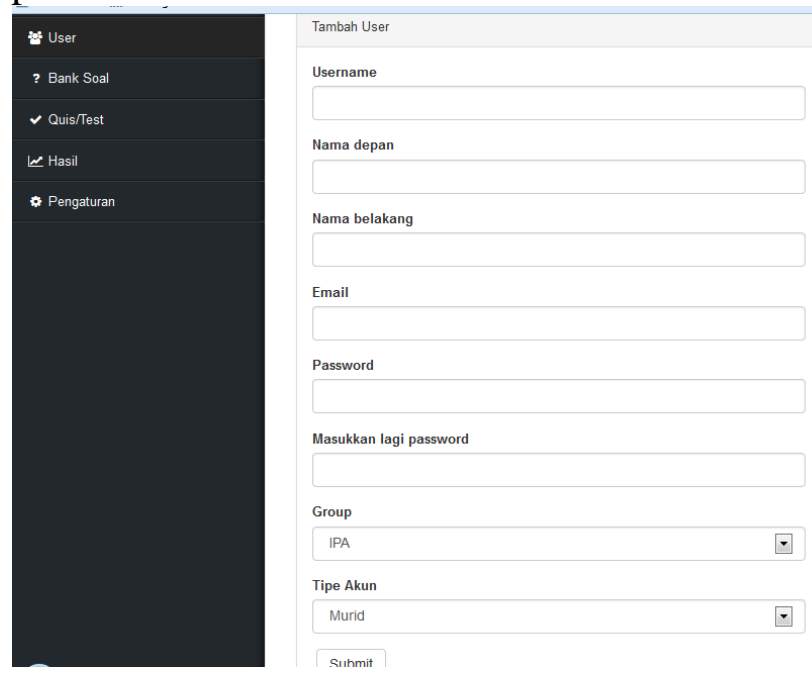

Gambar 6. Tampilan membuat user baru

\subsubsection{Menu Bank Soal}

Menu bank soal (Gambar 7) digunakan oleh admin admin untuk membuat, menghapus dan mengedit soal-soal.
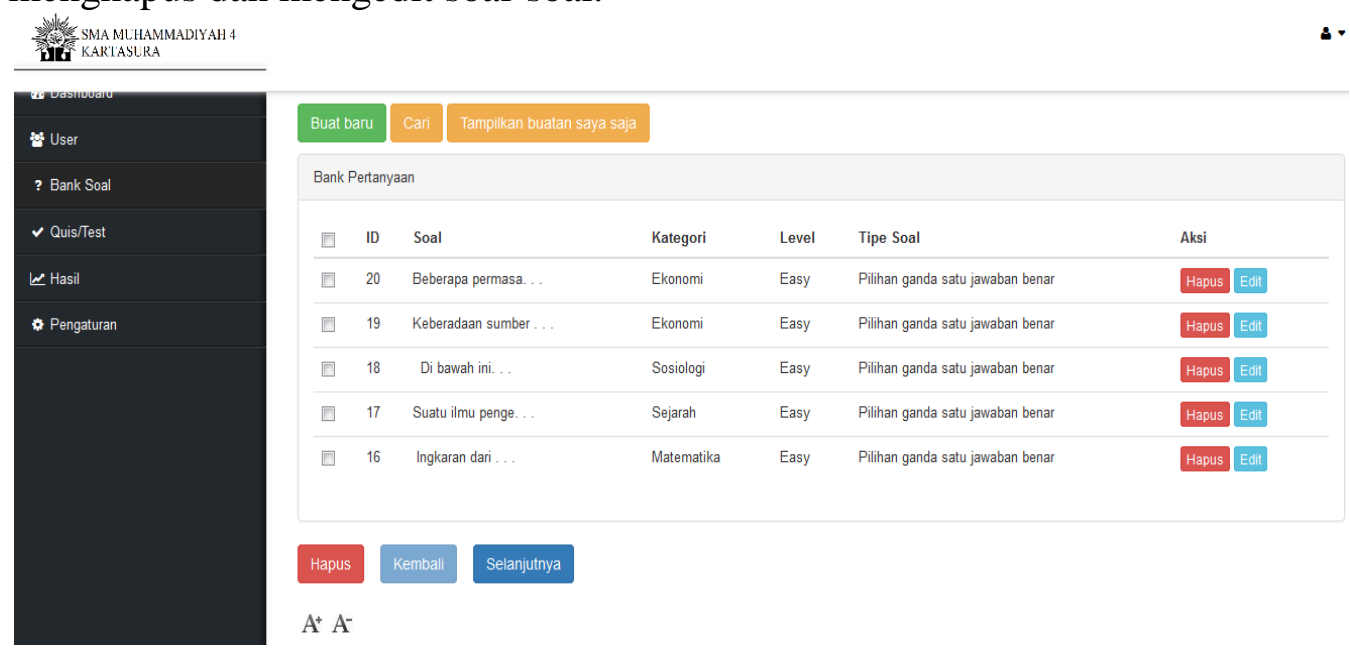

Gambar 7. Tampilan menu Bank Soal

Sub menu Buat Baru digunakan untuk membuat soal atau pertanyaan baru. Pembuatan soal baru dilakukan dengan memilih tipe soal, antara pilihan ganda satu jawaban benar atau pilihan ganda banyak jawaban benar. Langkah selanjutnya adalah pemilihan mata pelajaran yang ingin dibuat dan memilih tingkat kesulitan soal antara mudah, sedang atau sulit. Kemudian proses memasukkan soal dan penambahan deskripsi untuk soal dan penambahan pilihan jawaban yang benar dan salah kemudian di submit. Secara default, sesuai dengan kebutuhan, masing-masing soal mempunyai empat pilihan 
jawaban. Apabila ingin menambah jawabannya dilakuka dengan tambahkan jawaban lain pada kolom paling bawah yang sudah disediakan.

\subsubsection{Menu quiz/test}

Menu ini (Gambar 8) digunakan admin untuk membuat kuis atau test yang nantinya akan digunakan para siswa. Kuis tersebut dapat diikuti, di edit maupun di hapus oleh admin.
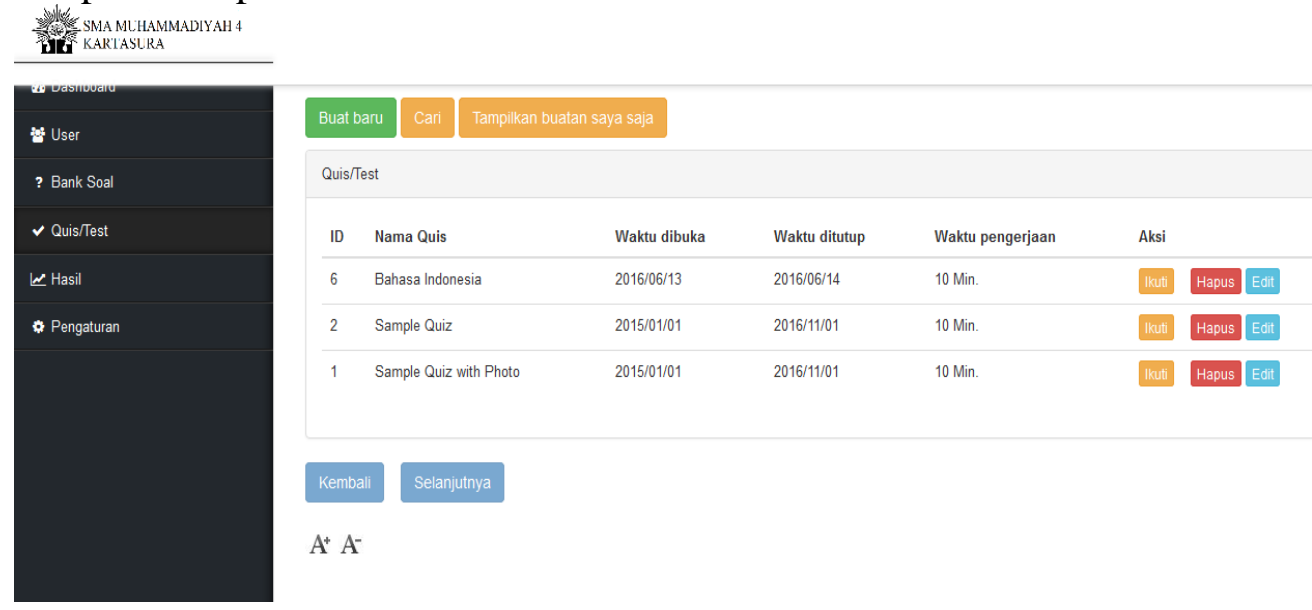

Gambar 8. Menu Quiz / Test

Pada bagian sub menu buat baru quiz/test digunakan untuk membuat kuis baru. Diantaranya terdiri dari menambahkan nama quiz itu sendiri serta tambahan deskripsi, selain hal tersebut ada durasi waktu untuk quiz, tanggal quiz dimulai dan diakhiri, persentase nilai untuk lulus, group untuk kuis, dapat melihat kuis setelah mengikuti kuis dan banyaknya mengikuti kuis. Kemudian submit quiz untuk menyelesaikannya.

\subsubsection{Menu Hasil}

Menu Hasil (Gambar 9) ini berisi tentang hasil kuis yang telah diikuti oleh pengguna. Informasi yang tersedia terdiri dari ID, username, nama depan, nama belakang, nama quiz, skor, persentase dan hasilnya. Selain itu pengguna dapat juga melihat lebih detail hasil tes dan pengguna dengan hak akses admin dapat menghapusnya.
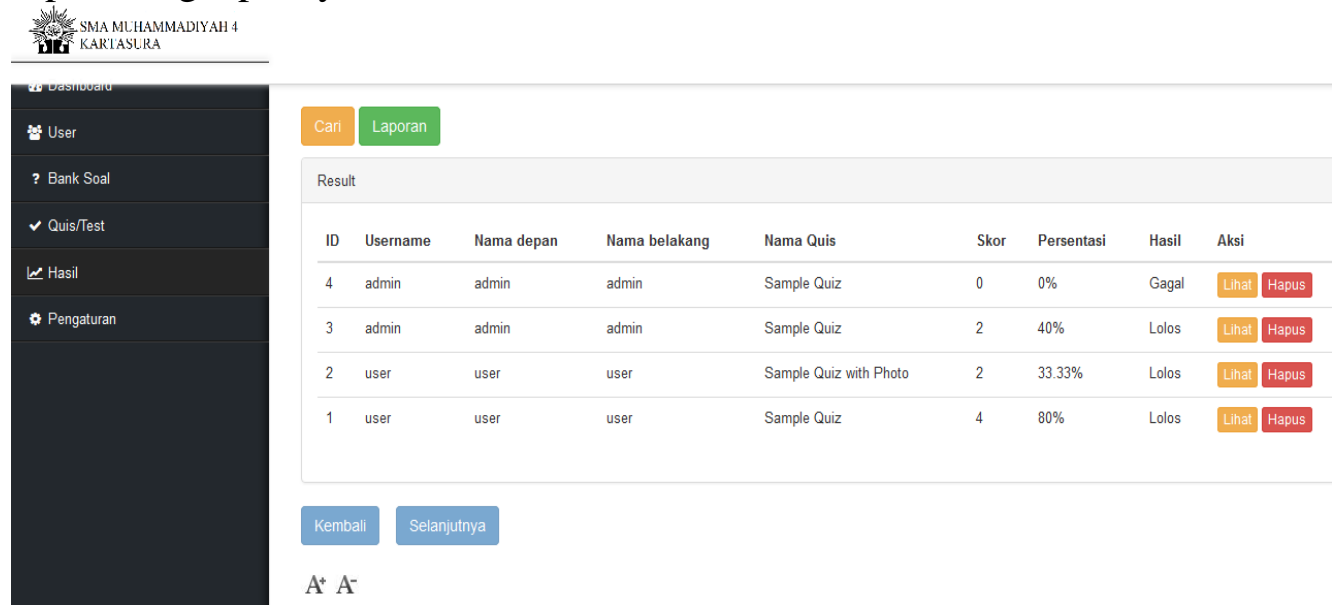

Gambar 9. Menu Hasil Quiz/Test 


\subsubsection{Menu pengaturan}

Pada menu ini (Gambar 10) terdapat pengaturan untuk group user yang terdiri dari (1) pembuatan, pengeditan dan menghapus user group; (2) pengaturan untuk pembuatan, pengeditan dan menghapus soal dan (3) pengaturan tingkat ke tingkat kesulitan soal.

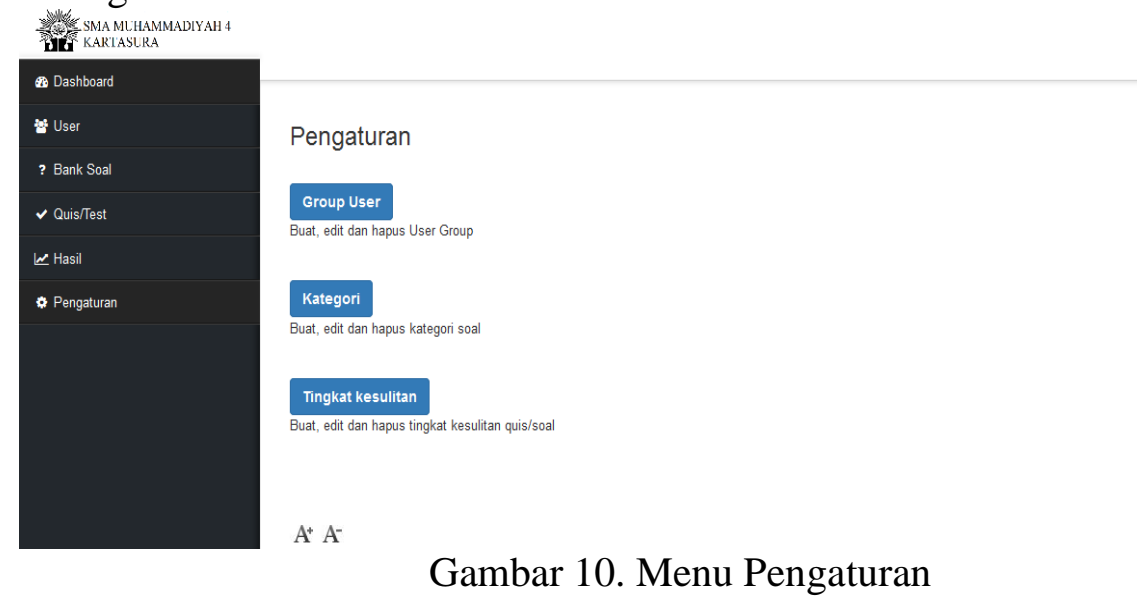

\subsubsection{Halaman Control Panel User}

Halaman Control Panel User ini digunakan apabila telah login ke website dengan username dan password yang ada. Terdiri dari dashboard, quiz/test dan hasil.

\subsubsection{Menu Dashboard User}

Menu dashboard adalah menu yang memberikan informasi mengenai test atau kuis yang sudah diikuti oleh pengguna. Saat pengguna masuk untuk pertama kalinya akan terdapat pesan bahwa chart tidak tersedia dikarenakan belum megikuti quiz atau tes. Apabila telah mengikuti beberapa quiz atau tes maka pada halaman dahsboard akan menampilkan chart tentang perkembangan mengikuti quiz/tes tersebut.

\subsubsection{Menu Quis/Test User}

Menu Quis/Test (Gambar 11) ini berisi daftar kuis yang dapat di ikuti user sesuai group user yang telah diatur oleh admin. Terdapat juga penjelasan tentang quiz yaitu terdiri dari ID, nama quiz, waktu dibuka, waktu ditutup, waktu pengerjaan dan aksi untuk mengikuti.
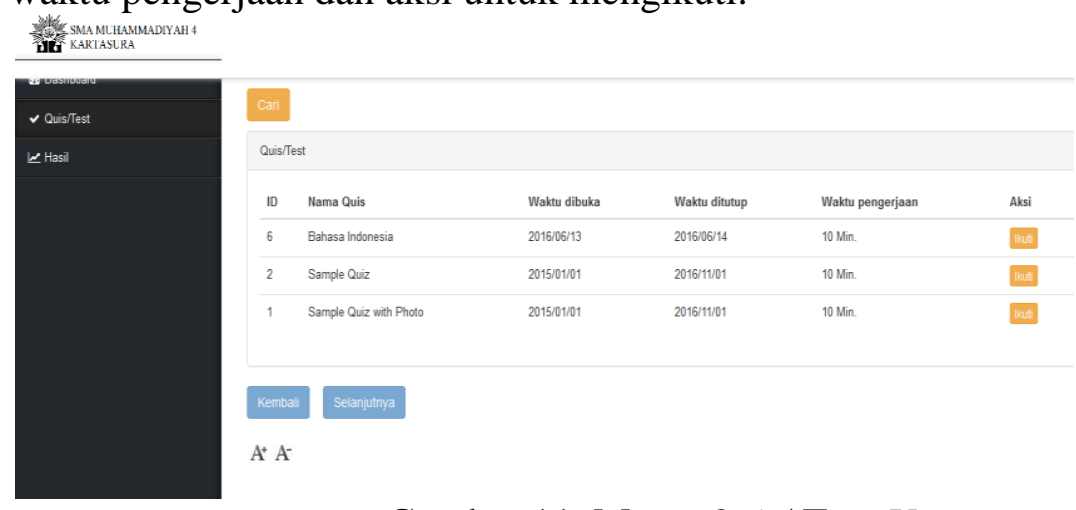

Gambar 11. Menu Quiz/ Test User 


\subsubsection{Menu Hasil}

Halaman hasil ini berisi tentang hasil dari quiz yang telah diikuti oleh user. Informasi yang ditampilkan pada menu ini terdiri dari ID, username, nama depan, nama belakang, nama quiz, skor, persentasi, hasil dan yang terakhir adalah aksi untuk melihat lebih detail hasil dari quiz atau menghapus hasilnya.

\subsection{Pembahasan}

Pembuatan perancangan sistem ujian berbasis website telah selesai dibuat sesuai dengan tujuan yaitu membuat latihan ujian yang berbasis komputer agar dapat dilaksanakan secara mudah, efisien, dengan hasil penilaian secara langsung dapat diketahui. Sistem yang dibuat mempunyai fitur untuk menampilkan daftar pengguna dan admin yang bisa login. Untuk admin terdapat beberapa menu yaitu halaman utama, halaman untuk membuat kategori kuis, halaman untuk menambahkan user dan admin, halaman untuk membuat soal, halaman untuk melihat hasil kuis yang telah di ikuti user,serta halaman untuk mengatur website. Untuk user terdapat beberapa menu yaitu halaman utama, halaman untuk mengikuti kuis dan halaman hasil perolehan nilai dari kuis yang sudah di ikuti.

Setelah selesai proses pengujian secara teknis yang menunjukkan semua fitur bisa bekerja dengan baik, sistem yang dibuat diuji dengan menggunakan berbagai macam web browser terutama dua buah web browser yang paling banyak dipakai penguna meliputi Google Chrome dan Mozilla Firefox. Sistem yang dibuat sudah responsif sehingga tampilannya mampu menyesuaikan ukuran layar perangkat yang digunakan untuk mengakses sistem secara otomatis.

Tahapan selanjutnya adalah sistem yang sudah dionlinekan diujikan kepada calon pengguna meliputi guru dan siswa SMA Muhammadiyah 4 Kartasura. Pengujian mengambil sampel sebanyak 19 siswa yang terdiri dari 13 siswa kelas XI dan 6 siswa kelas X yang ada di SMA Muhammadiyah 4 Kartasura. Pertama-tama siswa dan guru dilatih bagaimana menjalankan sistem, kemudian diminta untuk mengerjakan soal ujian dengan sistem online dan kemudian diminta mengisi kuesioner yang sudah disiapkan. Waktu pelaksanaan pelatihan dan pengujian adalah pada tanggal 16 Juni 2016 pukul 10.00 WIB di salah satu ruang kelas SMA Muhammadiyah 4 Kartasura. Data hasil pengisian kuesioner oleh siswa dapat dilihat pada Tabel. 1.

Tabel 1. Hasil Presentase Kuisioner (Keterangan: $\mathrm{SP}=$ sangat puas, $\mathrm{P}=$ puas, $\mathrm{KP}=$ kurang puas, $\mathrm{TP}=$ tidak puas)

\begin{tabular}{|c|l|c|c|c|c|c|}
\hline \multirow{2}{*}{ No } & \multicolumn{1}{|c|}{ Kriteria Penilaian } & \multicolumn{5}{|c|}{ Jawaban } \\
\cline { 3 - 6 } & & SP & P & CP & KP & TP \\
\hline 1 & Kecepatan loading & $20 \%$ & $20 \%$ & $60 \%$ & $0 \%$ & $0 \%$ \\
\hline 2 & Kecepatan pindah halaman web & $10 \%$ & $20 \%$ & $70 \%$ & $0 \%$ & $0 \%$ \\
\hline 3 & $\begin{array}{l}\text { Fungsi situs mendukung proses } \\
\text { belajar }\end{array}$ & $30 \%$ & $60 \%$ & $10 \%$ & $0 \%$ & $0 \%$ \\
\hline 4 & Kecepatam akses & $10 \%$ & $40 \%$ & $30 \%$ & $0 \%$ & $0 \%$ \\
\hline 5 & Tampilan website yang disajikan & $20 \%$ & $60 \%$ & $20 \%$ & $0 \%$ & $0 \%$ \\
\hline 6 & $\begin{array}{l}\text { Desain halaman muka baik } \\
\text { (interface) }\end{array}$ & $5 \%$ & $80 \%$ & $15 \%$ & $0 \%$ & $0 \%$ \\
\hline 7 & Huruf mudah dibaca & $30 \%$ & $30 \%$ & $40 \%$ & $0 \%$ & $0 \%$ \\
\hline 8 & Desain layout (desain tata letak) & $10 \%$ & $40 \%$ & $50 \%$ & $0 \%$ & $0 \%$ \\
\hline
\end{tabular}


Tabel 1. Lanjutan

\begin{tabular}{|c|l|c|c|c|c|c|}
\hline \multirow{2}{*}{ No } & \multirow{2}{*}{ Kriteria Penilaian } & \multicolumn{5}{|c|}{ Jawaban } \\
\cline { 3 - 7 } & SP & P & CP & KP & TP \\
\hline 9 & Komposisi warna website & $20 \%$ & $30 \%$ & $50 \%$ & $0 \%$ & $0 \%$ \\
\hline 10 & Struktur menu yang disajikan & $30 \%$ & $30 \%$ & $40 \%$ & $0 \%$ & $0 \%$ \\
\hline 11 & Alamat website mudah diingat & $20 \%$ & $70 \%$ & $10 \%$ & $0 \%$ & $0 \%$ \\
\hline 12 & $\begin{array}{l}\text { Kecepatan akses dalam menjawab } \\
\text { soal }\end{array}$ & $10 \%$ & $60 \%$ & $30 \%$ & $0 \%$ & $0 \%$ \\
\hline 13 & Kemudahan dalam menjawab soal & $10 \%$ & $60 \%$ & $30 \%$ & $0 \%$ & $0 \%$ \\
\hline 14 & Soal mudah di pahami dan di baca & $20 \%$ & $70 \%$ & $10 \%$ & $0 \%$ & $0 \%$ \\
\hline 15 & Warna tulisan & $10 \%$ & $80 \%$ & $5 \%$ & $0 \%$ & $0 \%$ \\
\hline 16 & Tata letak teks & $15 \%$ & $60 \%$ & $20 \%$ & $0 \%$ & $0 \%$ \\
\hline 17 & Kejelasan kalimat dalam tulisan & $20 \%$ & $70 \%$ & $10 \%$ & $0 \%$ & $0 \%$ \\
\hline 18 & $\begin{array}{l}\text { Mudah berinteraksi dalam } \\
\text { menjalankan website }\end{array}$ & $20 \%$ & $10 \%$ & $70 \%$ & $0 \%$ & $0 \%$ \\
\hline 19 & Desain website & $15 \%$ & $80 \%$ & $5 \%$ & $0 \%$ & $0 \%$ \\
\hline
\end{tabular}

Manfaat yang diperoleh dari penerapan sistem ujian online diketahui dari perbandingan keadaan sebelum dan sesudah diterapkannya sistem ujian online dapat dilihat pada Tabel 2.

Tabel 2. Perbandingan kondisi sebelum dan sesudah diterapkannya sistem latihan ujian online.

\begin{tabular}{|l|l|}
\hline \multicolumn{1}{|c|}{$\begin{array}{c}\text { Kondisi Sebelum } \\
\text { Diterapkannya Sistem }\end{array}$} & \multicolumn{1}{|c|}{ Kondisi Sesudah Diterapkannya Sistem } \\
\hline $\begin{array}{l}\text { Siswa belum terbiasa dalam } \\
\text { mengerjakan soal ujian dengan } \\
\text { berbasis komputer }\end{array}$ & $\begin{array}{l}\text { Siswa sudah terampil dalam menggunakan sistem } \\
\text { ujian } \text { online. }\end{array}$ \\
\hline $\begin{array}{l}\text { Guru hanya bisa memberikan } \\
\text { latihan ujian dengan metode } \\
\text { ujian berbasis kertas. }\end{array}$ & $\begin{array}{l}\text { Guru mempunyai kemampuan untuk mengelola } \\
\text { ujian dengan berbasis sistem online meliputi } \\
\text { membuat soal, mengupload soal dalam sistem, } \\
\text { mengevaluasi hasil latihan ujian siswa. }\end{array}$ \\
\hline
\end{tabular}

\section{KESIMPULAN DAN SARAN}

\subsection{Kesimpulan}

Berdasarkan hasil pengujian yang dilakukan dapat disimpulkan bahwa sistem latihan ujian online yang dibangun sudah memenuhi kebutuhan di SMA Muhammadiyah 4 Kartasura dan siap untuk diterapkan. Dari hasil pengujian yang dilakukan kepada siswa dan guru menunjukkan bahwa $70 \%$ merasa puas bahwa website dapat dioperasikan dengan baik dan mendukung dalam proses belajar mengajar. Dengan adanya website SMA Muhammadiyah 4 Kartasura sendiri dapat memberikan kemudahan terhadap siswa-siswi di dalam mengerjakan latihan ujian yang berbasis komputer agar dapat dilaksanakan secara mudah, efisien, dengan hasil penilaian secara langsung dapat diketahui.

\subsection{Saran}

Penelitian ini bisa dilanjutkan misalnya dengan menambahi sistem pemberitahuan nilai hasil latihan ujian nasional kepada orangtua dengan sistem sms gateway. 


\section{PERSANTUNAN}

Pembuatan dan penerapan sistem ujian online ini didanai oleh Direktorat Riset dan Pengabdian pada Masyarakat Kementerian Riset dan Pendidikan Tinggi (DRPM Kemenristekdikti) melalui skim pengabdian Ipteks bagi Masyarakat (IbM) tahun anggaran 2016. Tim pelaksana mengucapkan terima kasih kepada Pimpinan dan segenap guru dan siswa SMA Muhammadiyah 4 Kartasura yang telah bersedia menjadi mitra pengabdian ini dan berpartisipasi dalam pengujian sistem yang dibuat. Penerapan sisttem latihan ujian online ini melibatkan tiga orang mahasiswa yaitu Rahma Fitri Wahadati, Kunti Dwi Narwattu Jati, Unsta Nastiti Lingga Rastari dalam rangka Praktek Kerja Nyata (PKN) pada Program Studi Informatika FKI UMS.

\section{DAFTAR PUSTAKA}

Rivai, I. dan Supriyono, H. (2016). Aplikasi Toko Online (E-Commerce) Berbasis PHP dan MySQL. Artikel Publikasi Tugas Akhir Tingkat Sarjana Pada Program Studi Informatika Universitas Muhammadiyah Surakarta, Tidak Diterbitkan.

Sinurat, S. I. S.; Yunanto, W. \& Fadhli, M. (2012). Implementasi media pembelajaran interaktif sekolah dasar kelas 5 ipa dan ips menggunakan html 5. Jurnal Sistem Informasi, Vol 1 September 2012, pp.1-10

Supriyono, H. \& Sari, C.P. (2015). Pemilihan Rumah Tinggal Menggunakan Metode Weighted Product. Khazanah Informatika, Vol. I No. 1 , Desember 2015, Online ISSN: 2477-698X, pp. 23-28.

Supriyono, H., Saputro, N. A. \& Pradessya, R. A. (2016). Rancang Bangun Sistem Informasi Manajemen Presensi Berbasis SMS Gateway (Studi Kasus : SMP Muhammadiyah 1 Kartasura). Prosiding The 3rdUniversty Research Coloquium 2016. 13 Februari 2016. ISSN 2407-9189, pp. 1-15 